\title{
Population Biology of the Rhizoctonia solani Complex
}

\author{
M. A. Cubeta and R. Vilgalys
}

First author: Department of Plant Pathology, North Carolina State University, Plymouth 27692; second author: Department of Botany, Duke University, Durham, NC 27708.

Accepted for publication 22 January 1997.

The Rhizoctonia solani complex represents an economically important group of soilborne basidiomycete pathogens that occur on many plant species throughout the world (41). Identification and study of Rhizoctonia species has always presented a challenge because of their ill-defined taxonomy and our poor understanding of their natural history. Although identification of isolates as $R$. solani is largely dependent on vegetative characters, members of this group are known to be associated with a Thanatephorus teleomorph, or sexual stage. Several recent reviews discuss the taxonomy of different groups in Rhizoctonia $(34,41,44)$. Although previous research has focused primarily on taxonomic characterization and identification of $R$. solani, very little information about their population biology and genetics is available. In this paper, we review some recent progress in understanding the population biology and genetics of fungi in the $R$. solani complex and discuss possible research avenues for investigating $R$. solani genetic diversity in natural populations.

\section{Anastomosis Grouping}

The study of population biology and genetics in Rhizoctonia has been confounded by the growing realization that $R$. solani is actually a large species complex composed of many genetically distinct groups with very diverse life histories $(34,41)$. Current classification within the $R$. solani complex is based largely on grouping of isolates into anastomosis groups (AG). At least 12 AG have been described within the $R$. solani complex (Table 1). Many AG, including AG1 through 4, 6, 8, and 9, have been subdivided further into subgroups that differ for one or more biochemical, genetic, or pathogenic characteristics $(16,23,24,26,28)$. These studies all suggest that genetically diverse AG and their subgroups represent independent evolutionary groupings within $R$. solani (44).

Anastomosis grouping still represents the single most important advance in our understanding of the genetic diversity within Rhizoctonia. Adams (1) recently stated that "outsiders frequently complain about preoccupation with the characterization and identification of $R$. solani AG and subgroups...but these studies have matured our concept of the evolutionary unit in Rhizoctonia." Although the mechanisms and biological relevance of anastomosis reactions are still not completely understood, they are believed to represent somatic interactions between genetically distinct or similar fungal individuals. Recent studies have contributed greatly to our understanding of somatic interactions in many fungi, including Rhizoctonia. The paradigm underlying all of these studies is the

Corresponding author: M. A. Cubeta

E-mail address: cub@plymouth.ces.ncsu.edu

Publication no. P-1997-0131-020

(C) 1997 The American Phytopathological Society concept of fungal individualism established by Rayner et al. (3739), which shows that genetically distinct individuals can be distinguished by somatic incompatibility interactions. In $R$. solani, somatic incompatibility (or compatibility) is observed most directly at the microscopic level between paired isolates (40). Pairing of isolates belonging to the same AG results in hyphal fusion (anastomosis), leading to either acceptance (self-pairings) or rejection (somatic incompatibility). Pairings between AG do not result in hyphal fusion, suggesting greater genetic differences between isolates (i.e., different species, etc.).

The criteria used to delimit AG in $R$. solani are summarized in Table 2 (28). Four classes of reactions can be distinguished according to the degree of interaction (and presumed genetic relatedness) between hyphae from interacting isolates. Interactions between $\mathrm{AG}(\mathrm{C} 0$ and $\mathrm{C} 1)$ generally result in little or no hyphal fusion between isolates. Within an $\mathrm{AG}$, two types of interactions (C2 and C3) are most relevant for the study of population biology. The $\mathrm{C} 2$ reaction, also referred to as the killing reaction, represents a somatic incompatibility response between genetically distinct individuals. The $\mathrm{C} 3$ reaction (perfect fusion) between two isolates is indicative of genetic identity or near-identity. For population studies, C2 reactions provide a means of defining individuals within a population, whereas $\mathrm{C} 3$ reactions are expected to occur between clones or very closely related individuals. The ability to distinguish between $\mathrm{C} 2$ and $\mathrm{C} 3$ reactions provides a means of identifying what constitutes a population in different $R$. solani AG but only rarely has been used to characterize $R$. solani populations $(28,35)$.

Interpretation of anastomosis reactions is not always straightforward. The four hyphal interaction phenotypes ( $\mathrm{C} 0$ to $\mathrm{C} 3)$ represent a continuum, and reproducibility of $\mathrm{AG}$ interactions can be affected by factors such as laboratory environment, nutritional conditions, and genetic instability $(14,17,51)$. In general, adherence to standardized protocols for AG testing appears to provide more reproducible results with certain Rhizoctonia spp. (40). The modified 4',6-diamidino-2-phenylindole staining procedure recently described by Kulik and Dery (20) also may be a useful tool for studying Rhizoctonia population biology and genetics by substantially reducing the time required to determine microscopic hyphal interaction phenotypes. The development of less laborious methods of determining somatic interactions and genetic relatedness of Rhizoctonia isolates is needed.

Another important factor influencing the outcome of AG pairings is the genetic state of interacting isolates, which may be either homo- or heterokaryotic or both (1). For pairing studies involving homokaryotic strains especially, sexual interactions also are possible, and these may complicate interpretation of anastomosis interactions. The dynamics of asexual and sexual interactions are poorly understood in most fungi $(3,39)$, especially in $R$. solani, because 
heterokaryons are not easily distinguished from homokaryons (1, 10). The occurrence of homokaryons in nature also increases the possibility of interactions between homo- and heterokaryotic isolates. The role of all these hyphal interactions in the interpretation of anastomosis tests is not well understood and deserves further investigation in a population biology context.

\section{Looking Beyond the AG}

The separation of $R$. solani into distinct AG and subgroups provides a long-sought foundation for examining population biology and genetics. Depending on one's definition, several hierarchical organism groupings below the AG level might be considered as species, populations, individuals, and clones. The population level (and lower) is still the least well understood in $R$. solani, and the population genetic structure also remains virtually unknown within any $R$. solani AG.

\section{Mating Compatibility Systems}

Some of the first questions addressed by Rhizoctonia workers focused on determining the type of mating compatibility system associated with specific AG. Mating systems govern patterns of sexual reproduction in natural populations and have a direct effect on population structure. In other basidiomycetes, heterothallic mating systems promote higher levels of outcrossing, whereas homothallism can lead to a higher proportion of inbreeding in populations through self-mating. Homothallism by itself, however, does not necessarily prevent outcrossing from occurring in homothallic fungal species, which has been observed with other fungal genera (3).

Unfortunately, analysis of mating compatibility in $R$. solani is not as straightforward as in other groups of basidiomycetes that have regular monokaryotic and dikaryotic life histories. In all groups of $R$. solani, hyphae of both homokaryons and heterokaryons are multinucleate and lack clamp connections and, thus, lack diagnostic morphological characteristics for detecting mating reactions. Instead, researchers studying $R$. solani have traditionally relied on the formation of aerial tuft hyphae within the interaction zone between paired homokaryons to assess heterokaryon formation (36, 46). In our laboratory, studies with DNA markers to confirm crosses have found that tuft formation may not always be associated with heterokaryon formation (10). Assessment of mating behavior is further complicated by the fact that most field isolates of $R$. solani that sporulate in nature do not readily sporulate in vitro $(4,34)$.

Several AG in $R$. solani that have been investigated possess either homothallic (self-fertile) or bipolar, heterothallic mating systems (Table 1). At least two AG (AG1-IC and AG4) have heterothallic, bipolar mating systems controlled by a single genetic factor with multiple alleles (1). Initial studies suggest that the mating system of AG8 is also bipolar (48). Several AG with heterothallic mating systems exhibit homothallic behavior as well, through a process known as homokaryotic fruiting (2). Homothallic mating behavior has been reported for several AG, including AG1 through 4. Homothallism can have predictable consequences for population structure, because progeny that arise through homothallic selfmating are genetically identical to each other and to their parent. Both heterothallic and homothallic AG also may undergo recombination through the process of heterokaryon-homokaryon (di-mon) mating originally described by Buller (8). For di-mon mating to occur, basidiospores must germinate on soil or plant tissue and produce a viable homokaryotic mycelium capable of interacting with resident heterokaryotic mycelium. However, previous studies have shown that Thanatephorus basidiospores are difficult to germinate and that single basidiospore isolates usually are less virulent and have more limited saprophytic capabilities than their parental heterokaryon $(9,49)$. Although di-mon mating in $R$. solani is easily demonstrated in laboratory crosses $(10,17)$, little is known about its prevalence in populations.

The extent of homothallic versus heterothallic reproduction in most $\mathrm{AG}$ and subgroups is unknown. In most $R$. solani $\mathrm{AG}$ and subgroups, the asexual stage often is viewed as the predominant stage in their life history, although the sexual stage of many $R$. solani AG (e.g., AG1 through 5) is frequently observed in agricultural fields. Hymenia of Thanatephorus spp. consisting of basidia, basidiospores, and sterigmata often form near the base of a plant within the canopy at or just above the soil surface. More critical studies are needed to assess the prevalence of homothallic and other forms of asexual reproduction in natural populations. In general, the relative importance of sexual and asexual reproduc-

TABLE 1. List of anastomosis groups (AG) in the Rhizoctonia solani complex, with information about mating systems, genetic markers, and population structure

\begin{tabular}{|c|c|c|c|}
\hline Anastomosis group & Mating system & Genetic markers employed $^{\mathrm{a}}$ & Population structure \\
\hline AG1 & Primarily heterothallic ${ }^{b}$ & Isozymes, rDNA, and RAPD RFLP & Outcrossing \\
\hline AG2 & Presumed homothallic & Isozymes, rDNA, and RAPD RFLP & Clonal/outcrossing \\
\hline AG3 & Presumed homothallic & Isozymes, DNA fingerprinting, rDNA, and scn DNA RFLP & Clonal/outcrossing \\
\hline AG5 & $?$ & rDNA RFLP & $?$ \\
\hline AG6 & ? & rDNA RFLP & ? \\
\hline AG7 & $?$ & rDNA RFLP & $?$ \\
\hline AG8 & Primarily heterothallic ${ }^{b}$ & Isozymes, DNA fingerprinting, rDNA, and RAPD RFLP & Clonal/outcrossing \\
\hline AG11 or AGBI & ? & ? & ? \\
\hline
\end{tabular}

${ }^{a}$ RAPD = randomly amplified polymorphic DNA; rDNA = ribosomal DNA; RFLP = restriction fragment length polymorphism; scn DNA = single-copy nuclear DNA; and ? = data not available.

${ }^{\mathrm{b}}$ Several AG with heterothallic mating systems may exhibit homothallic behavior as well through a process known as homokaryotic fruiting.

TABLE 2. Classification of hyphal anastomosis reactions using the criteria of MacNish et al. (28) to delimit anastomosis groups (AG) in Rhizoctonia solani

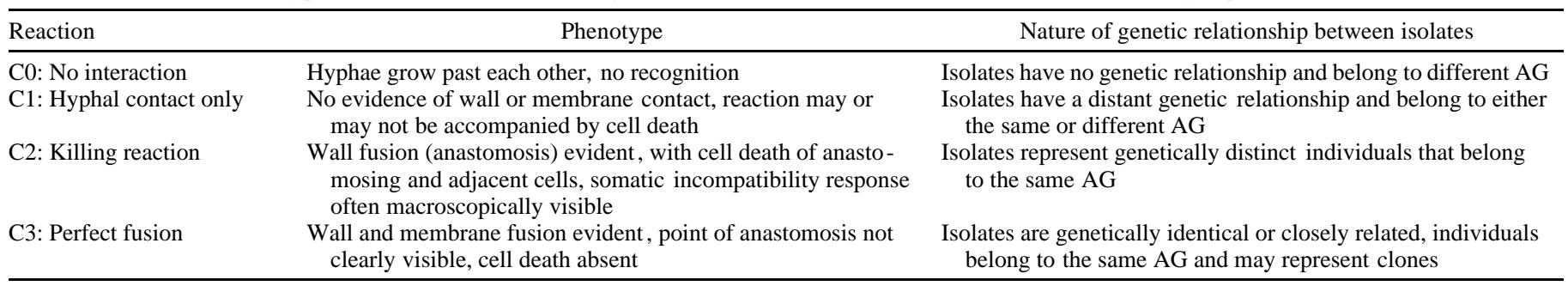


tion and their relative contribution to genetic diversity and structure in natural populations has not been addressed in many fungi (3). Is the observed genetic diversity in different $R$. solani AG and subgroups associated with asexual or sexual reproduction or a combination of both?

Adams' recent review (1) provides some interesting insights into the significance of asexual and sexual reproductive strategies in $R$. solani. For some $R$. solani AG, wind-dispersed basidiospores may serve as the primary inocula for inciting foliar diseases of various cultivated plant species under favorable environmental conditions (32). In general, however, basidiospores are not the primary inocula responsible for infections, and most Rhizoctonia diseases result from initial infection by propagules (sclerotia or mycelia, often in association with plant debris) that are able to survive for many years in soil. Disease resulting from infection via sclerotia or mycelia often appear as clusters (aggregates) of infected plants within a field, whereas disease resulting from basidiospore infection often appears as a random, uniform pattern of infected plants throughout the field (32). Although basidiospores may not be of epidemiological significance for most Rhizoctonia root and seedling diseases during a growing season, they may have important ecological and population consequences. Innate mechanisms of basidiospore dispersal (i.e., repetitive spore germination and forcible discharge at night), as well as the immigration and vegetative spread of sclerotia and mycelium associated with agricultural practices, are well documented and would contribute significantly to the temporal and spatial distribution of $R$. solani genotypes in natural populations. Meiotic reproduction may provide a mechanism for generating genetic diversity in a population even if the primary mode of reproduction is asexual (30).

\section{Molecular Markers in Rhizoctonia-The Need for Population Genetics}

Future advances in understanding Rhizoctonia population biology almost certainly will rely heavily on the application of genetic markers to characterize the genotypic structure of populations. A variety of molecular markers have been applied to the study of Rhizoctonia spp. at different taxonomic levels (Table 3). The majority of these studies have been aimed primarily at establishing genetic differences between AG and subgroups $(34,44)$. Awareness of the differences between groups should now help researchers focus attention on the considerable amount of genetic variation that exists within AG.

What are the characteristics of a "good" genetic marker for examining populations? Some of the molecular approaches with potential for addressing genetic diversity at the population level in $R$. solani include isozymes $(23,25,42)$, restriction fragment length polymorphism (RFLP) $(11,15)$, DNA fingerprinting $(5,29,45)$, and randomly amplified polymorphic DNA (RAPD) $(12,50)$. One criterion to consider is the utility of a particular marker for inferring an

TABLE 3. Genetic markers employed previously to study genetic variation in different Rhizoctonia solani anastomosis groups (AG) and their utility at different taxonomic levels

\begin{tabular}{lcccc}
\hline & \multicolumn{3}{c}{ Utility of genetic marker } & \\
\cline { 2 - 3 } Genetic marker $^{\mathrm{a}}$ & $\begin{array}{c}\text { Above species } \\
\text { level }\end{array}$ & $\begin{array}{c}\text { Species/AG } \\
\text { level }\end{array}$ & $\begin{array}{c}\text { Population } \\
\text { level }\end{array}$ & Reference \\
\hline $\begin{array}{l}\text { Cellular fatty acids } \\
\text { DNA fingerprinting }\end{array}$ & $\mathrm{X}$ & $\mathrm{X}$ & $\mathrm{X}$ & $\begin{array}{c}16 \\
\text { DNA/DNA }\end{array}$ \\
$\begin{array}{l}\text { hybridization } \\
\text { Electrophoretic }\end{array}$ & $\mathrm{X}$ & $\mathrm{X}$ & & 21,45 \\
$\quad$ karyotyping & & $\mathrm{X}$ & $\mathrm{X}$ & 18 \\
$\begin{array}{l}\text { Isozymes/zymograms } \\
\text { RAPD RFLP }\end{array}$ & & $\mathrm{X}$ & $\mathrm{X}$ & $23,26,28,42$ \\
& $\mathrm{X}$ & $\mathrm{X}$ & $\mathrm{X}$ & $10,12,43,47$, \\
rDNA RFLP & & $\mathrm{X}$ & & $11,15,24-26$, \\
scn DNA RFLP & & $\mathrm{X}$ & $\mathrm{X}$ & 15 \\
\hline
\end{tabular}

${ }^{\text {a }}$ RAPD = randomly amplified polymorphic DNA; rDNA = ribosomal DNA; RFLP = restriction fragment length polymorphism; and scn DNA = single-copy nuclear DNA. unambiguous genotype for each individual (strain) in a given population. Single-locus genetic markers such as isozymes and DNAbased RFLP are probably most useful for analyzing population structure because they provide information on a locus-by-locus basis that can be analyzed by standard population genetic methods. To identify genetically distinct strains (clones) in a population, methods that survey many loci at once (such as RAPD or DNA fingerprinting) might provide a higher level of discrimination than single-locus markers. Because each method has its own advantages and limitations, in many instances it may be desirable to use a combination of different methods. Issues that need to be considered concerning any molecular method include practical considerations regarding methodological and logistical aspects (sample preparation, reproducibility, cost, and safety), as well as analytical considerations regarding the genetic basis of a marker (e.g., sensitivity to genetic differences and dominance).

A variety of cytoplasmic genetic elements have been described in $R$. solani, including double-stranded RNA (dsRNA) and DNA plasmids (reviewed in reference 44 ), which may potentially be useful genetic markers. Although some studies have suggested a role for these cytoplasmic elements in pathogenicity, more extensive surveys of both plasmid and dsRNA elements have failed to find any clear associations $(6,7)$. Although several studies also have demonstrated that dsRNA and plasmid diversity are clearly linked with differences among AG, more work is needed to understand the patterns of cytoplasmic element diversity within an AG. For example, are plasmids or dsRNAs transmitted via hyphal anastomosis when $\mathrm{C} 2$ or $\mathrm{C} 3$ interactions occur or can they be transmitted via basidiospores? No studies, to our knowledge, have attempted to address the distribution and transmission of cytoplasmic elements as genetic markers in $R$. solani populations. Such studies clearly are needed before we are able to understand more about the occurrence and transmission of cytoplasmic elements in natural populations.

Mitochondrial DNA (mtDNA) is another untapped source of cytoplasmically inherited markers for investigating Rhizoctonia population biology. In other groups of fungi, patterns of mtDNA diversity have revealed a great deal about patterns of clonality and genetic structure in agricultural and wild fungal populations (13, 19,31). As with dsRNA and plasmids, very little is known about mtDNA diversity in different $R$. solani AG. Future studies need to address basic questions about the transmission and inheritance of mtDNA, as well as the utility of mtDNA as a marker for population genetic studies. For example, what is the relationship between mtDNA haplotype and $R$. solani AG/subgroup? Are certain mtDNA haplotypes associated with specific dsRNA and plasmids? How comparable is the genetic diversity of different $R$. solani AG/subgroups based on nuclear versus mitochondrial-based DNA markers?

Few of the studies described above have gone much further than to simply demonstrate the potential utility of genetic markers for understanding population biology in Rhizoctonia. Future studies need to address many fundamental questions about the life history of $R$. solani in natural populations: (i) what is the genetic nature of individuals and populations; (ii) does recombination occur; (iii) how prevalent is clonal reproduction; and (iv) how are populations established and maintained? In all cases, both variation and heritability of genetic markers need to be established. In addition, markers must be stable enough that different laboratories are able to repeat the results of different studies $(22,43)$.

\section{Population Biology}

In contrast to many papers presented in this symposium, the study of Rhizoctonia population biology and genetics is just beginning to emerge. Several recent studies on AG8 demonstrate how molecular markers might be integrated with hyphal anastomosis behavior to examine population biology in $R$. solani AG8. Most isolates belonging to AG8 are serious pathogens on cereal crops, especially in Australia, where they are associated with bare 
patch disease (27). Methods that have been used to characterize AG8 isolates include hyphal anastomosis, pectic isozymes (zymograms), RAPD, and DNA fingerprinting. Using hyphal anastomosis criteria and pectic zymograms, MacNish et al. (28) studied distribution patterns among AG8 isolates in several fields in West Australia. Hyphal anastomosis tests were performed to distinguish between self (C3) and non-self ( $\mathrm{C} 1$ and $\mathrm{C} 2)$ reactions among isolates from the same and different fields. Isolates from the same field showing self-identity (C3) reactions always belonged to the same pectic zymogram group (ZG), as would be expected for genetically identical strains (28). Based on these two criteria, their study also found that certain clones belonging to two ZG (ZG1-1 and 1-2) were distributed over very broad geographic distances, including West Australia, Washington, and Oregon. To date, five ZG have been identified within $R$. solani AG8 (ZG1-1 to 1-5), and isolates from the same disease patch usually belonged to the same ZG.

Hyphal anastomosis and pectic zymogram criteria also were used for extensive study of AG8 patch dynamics (28). Isolates between ZG produced a $\mathrm{C} 2$ hyphal anastomosis reaction, whereas isolates within a ZG produced either a $\mathrm{C} 2$ or $\mathrm{C} 3$ reaction. These results suggest a greater degree of genetic diversity within a ZG than was detected previously by pectic zymograms. MacNish (27) recently proposed the term "vegetatively compatible population" for a group of isolates that belonged to the same ZG and produced a C3 hyphal anastomosis reaction with each other.

In another study, Yang et al. (47) showed that isolates of AG8 from two locations in West Australia belonging to two pectic ZG were distinguished by RAPD fingerprints. Within each ZG, isolates were characterized by identical RAPD patterns, suggesting these AG8 isolates were clonal or very closely related. Together, these studies suggest that there is limited genetic variability and that extensive clonal reproduction is present within populations of $R$. solani AG8 in West Australia.

More recently, DNA fingerprinting probes that recognize highly repetitive DNA sequences have been developed to study $R$. solani AG8 (29) and AG3 (5) from South Australia. Matthew et al. (29) identified 15 DNA fingerprints for 16 AG8 isolates they examined. Two of the isolates shared a common DNA fingerprint pattern but were recovered $300 \mathrm{~km}$ apart, suggesting they might be clones. Another case of possible clonality for multiple isolates was presented by Balali et al. (5) for AG3 isolates from potato and soil in commercial potato fields in South Australia. Of 136 isolates examined, only 38 DNA fingerprints patterns were identified, and 1 DNA fingerprint was associated with $\sim 30 \%$ of the isolates. The repeated recovery of similar genotypes from various geographic regions strongly suggests a clonal population structure for AG3 and also possibly for AG8. In these and the other examples mentioned above, evidence concerning genetic structure would be strengthened by larger sample sizes (both within and among populations), as well as by more information about the genotypic data collected. Interpretation of DNA fingerprints in many fungi is complicated by the fact that individual bands are dominant and may not effectively distinguish homo- versus heterozygotes. In the absence of other evidence, DNA fingerprinting utilized in conjunction with somatic compatibility and pectic zymogram patterns is beginning to provide an initial picture of the genetic structure for some $R$. solani AG.

\section{Conclusions}

Future progress in understanding $R$. solani population biology will require a combination of the approaches discussed above, including detailed analysis of anastomosis behavior and mating reactions among isolates. Both types of studies (anastomosis and mating) would benefit greatly from judicious application of appropriate molecular genetic markers. The following characteristics would be especially informative for such markers: (i) single locus- specific (nuclear) markers for unambiguous assignment of genotypes to $R$. solani isolates - both isozyme and DNA-based (RFLP) markers are ideally suited for this purpose, because they are codominant and their inheritance can be easily demonstrated through crossing studies. (ii) DNA fingerprinting probes: multilocus genetic markers showing high levels of variation also are needed to assess genetic identity among isolates suspected of being clonal in origin. Methods such as DNA fingerprinting and RAPD profiling could be used in conjunction with hyphal anastomosis testing to assess hypotheses concerning clonal structure in populations. (iii) mtDNA markers (mtDNA RFLP) also could provide additional information about genetic relatedness, evolutionary origin, patterns of cytoplasmic inheritance, gene flow, and subdivision among populations.

Although a clearer understanding of the biology of $R$. solani is slowly emerging, many basic questions about the nature of populations and individuals need to be addressed. In contrast to most research programs aimed at a single species, Rhizoctonia researchers are still learning how to integrate population studies with existing knowledge about the complex biological nature of AG. Often, questions about species, populations, and individuals all must be addressed simultaneously. Future progress in this area will require coordinated and cooperative efforts between individual research groups investigating population biology within different $R$. solani AG using common approaches. In this manner, combined results from different laboratories would provide a better and more complete view of Rhizoctonia population biology.

\section{ACKNOWLEDGMENTS}

Portions of this work were supported by USDA grants 88-01007 and 91-00853. We thank F. Martin for organizing this symposium and P. E. Puryear for assistance with locating literature. Comments from two anonymous reviewers also were useful in revising this manuscript.

\section{LITERATURE CITED}

1. Adams, G. C. 1996. Genetics of Rhizoctonia species. Pages 101-116 in: Rhizoctonia Species: Taxonomy, Molecular Biology, Ecology, Pathology and Disease Control. B. Sneh, S. Jabaji-Hare, S. Neate, and G. Dijst, eds. Kluwer Academic Publishers, Dordrecht, Netherlands.

2. Adams, G. C., Jr., and Butler, E. E. 1982. A reinterpretation of the sexuality of Thanatephorus cucumeris anastomosis group four. Mycologia 74:793-800.

3. Anderson, J. B., and Kohn, L. M. 1995. Clonality in soilborne, plantpathogenic fungi. Annu. Rev. Phytopathol. 33:369-391.

4. Anderson, N. A. 1984. Variation and heterokaryosis in Rhizoctonia solani. Pages 367-382 in: The Ecology and Physiology of the Fungal Mycelium. D. H. Jennings and A. D. M. Rayner, eds. Cambridge University Press, Cambridge.

5. Balali, G. R., Whisson, D. L., Scott, E. S., and Neate, S. M. 1996. DNA fingerprinting probe specific to isolates of Rhizoctonia solani AG-3. Mycol. Res. 100:467-470.

6. Bharathan, N., and Tavantzis, S. M. 1990. Genetic diversity of doublestranded RNA from Rhizoctonia solani. Phytopathology 80:631-635.

7. Bharathan, N., and Tavantzis, S. M. 1991. Assessment of genetic relatedness among double-stranded RNAs from isolates of Rhizoctonia solani. Phytopathology 81:411-415.

8. Buller, A. H. R. 1931. Researches on Fungi. Vol. 2. Longmans, Green, and Co., London.

9. Butler, E. E. 1993. Rhizoctonia solani. Pages 87-112 in: Biology of Sclerotial-Forming Fungi. S. Lyda and C. M. Kenerley, eds. Texas Agricultural Experiment Station Press, College Station.

10. Cubeta, M. A., Briones, O. R., and Vilgalys, R. 1993. Reassessment of heterokaryon formation in Rhizoctonia solani anastomosis group 4. Mycologia 85:777-787.

11. Cubeta, M. A., Vilgalys, R., and Gonzalez, D. 1996. Molecular analysis of ribosomal RNA genes in Rhizoctonia fungi. Pages 81-86 in: Rhizoctonia Species: Taxonomy, Molecular Biology, Ecology, Pathology and Disease Control. B. Sneh, S. Jabaji-Hare, S. Neate, and G. Dijst, eds. Kluwer Academic Publishers, Dordrecht, Netherlands.

12. Duncan, S., Barton, J. E., and O'Brien, P. A. 1993. Analysis of variation in isolates of Rhizoctonia solani by random amplified polymorphic DNA 
assay. Mycol. Res. 97:1075-1082.

13. Gordon, T. R., and Okamoto, D. 1992. Variation within and between populations of Fusarium oxysporum based on vegetative compatibility and mitochondrial DNA. Can. J. Bot. 70:1211-1217.

14. Hyakumachi, M., and Ui, T. 1987. Non-self-anastomosing isolates of Rhizoctonia solani obtained from fields of sugarbeet monoculture. Trans. Br. Mycol. Soc. 89:155-159.

15. Jabaji-Hare, S. H., Meller, Y., Gill, S., and Charest, P. M. 1990. Investigation of genetic relatedness among anastomosis groups of Rhizoctonia solani using cloned DNA probes. Can. J. Plant Pathol. 12:393-404.

16. Johnk, J. S., and Jones, R. K. 1993. Differentiation of populations of AG-2-2 of Rhizoctonia solani by analysis of cellular fatty acids. Phytopathology 83:278-283.

17. Julian, M. C., Debets, F., and Keijer, J. 1996. Independence of sexual and vegetative incompatibility mechanisms of Thanatephorus cucumeris (Rhizoctonia solani) anastomosis group 1. Phytopathology 86:566-574.

18. Keijer, J., Houterman, P. A., Dullemans, A. M., and Korsman, M. G. 1996. Heterogeneity in electrophoretic karyotype within and between anastomosis groups of Rhizoctonia solani. Mycol. Res. 100:789-797.

19. Kohli, Y., and Kohn, L. M. 1996. Mitochondrial haplotypes in populations of the plant-infecting fungus Sclerotinia sclerotiorum: Wide distribution in agriculture, local distributions in the wild. Mol. Ecol. 5:773783.

20. Kulik, M. M., and Dery, P. D. 1995. Use of DAPI for anastomosis group typing of strains of the fungus Rhizoctonia solani. Biotech. \& Histochem. 70:95-98.

21. Kuninaga, S. 1996. DNA base sequence complementarity analysis. Pages 73-80 in: Rhizoctonia Species: Taxonomy, Molecular Biology, Ecology, Pathology and Disease Control. B. Sneh, S. Jabaji-Hare, S. Neate, and G. Dijst, eds. Kluwer Academic Publishers, Dordrecht, Netherlands.

22. Laroche, A., Gaudet, D. A., Schaalje, G. B., Erickson, R. S., and Ginns, J. 1995. Grouping and identification of low temperature basidiomycetes using mating, RAPD and RFLP analyses. Mycol. Res. 99:297-310.

23. Laroche, J. P., Jabaji-Hare, S. H., and Charest, P. M. 1992. Differentiation of two anastomosis groups of Rhizoctonia solani by isozyme analysis. Phytopathology 82:1387-1393.

24. Liu, Z. L., Domier, L. L., and Sinclair, J. B. 1993. ISG-specific ribosomal DNA polymorphism of the Rhizoctonia solani species complex. Mycologia 85:795-800.

25. Liu, Z., Nickrent, D. L., and Sinclair, J. B. 1990. Genetic relationships among isolates of Rhizoctonia solani anastomosis group-2 based on isozyme analysis. Can. J. Plant Pathol. 12:376-382.

26. Liu, Z. L., and Sinclair, J. B. 1993. Differentiation of intraspecific groups within anastomosis group I of Rhizoctonia solani using ribosomal DNA internal transcribed spacer and isozyme comparisons. Can. J. Plant Pathol. 15:272-280.

27. MacNish, G. C. 1996. Patch dynamics and bare patch. Pages 217-226 in: Rhizoctonia Species: Taxonomy, Molecular Biology, Ecology, Pathology and Disease Control. B. Sneh, S. Jabaji-Hare, S. Neate, and G. Dijst, eds. Kluwer Academic Publishers, Dordrecht, Netherlands.

28. MacNish, G. C., Carling, D. E., and Brainard, K. A. 1993. Characterization of Rhizoctonia solani AG-8 from bare patches by pectic isozyme (zymogram) and anastomosis techniques. Phytopathology 83:922-927.

29. Matthew, J., Herdina, and Whisson, D. 1995. DNA probe specific to Rhizoctonia solani anastomosis group 8. Mycol. Res. 99:745-750.

30. McDonald, B. A., Pettway, R. E., Chen, R. S., Boeger, J. M., and Martinez, J. P. 1995. The population genetics of Septoria tritici (teleomorph Mycospharella graminicola). Can. J. Bot. 73:S292-S301 .

31. Milgroom, M. G., and Lipari, S. E. 1995. Spatial analysis of nuclear and mitochondrial RFLP genotypes in populations of the chestnut blight fungus, Cryphonectria parasitica. Mol. Ecol. 4:633-642.
32. Naito, S. 1996. Basidiospore dispersal and survival. Pages 197-206 in: Rhizoctonia Species: Taxonomy, Molecular Biology, Ecology, Pathology and Disease Control. B. Sneh, S. Jabaji-Hare, S. Neate, and G. Dijst, eds. Kluwer Academic Publishers, Dordrecht, Netherlands.

33. O'Brien, P. A. 1994. Molecular markers in Australian isolates of Rhizoctonia solani. Mycol. Res. 98:665-671.

34. Ogoshi, A. 1987. Ecology and pathogenicity of anastomosis and intraspecific groups of Rhizoctonia solani Kühn. Annu. Rev. Phytopathol. 25: $125-143$.

35. Ogoshi, A., and Ui, T. 1983. Diversity of clones within an anastomosis group of Rhizoctonia solani Kühn in fields of white potatoes, sugar beets, and rice plants. Ann. Phytopathol. Soc. Jpn. 59:239-245.

36. Puhalla, J. E., and Carter, W. W. 1976. The role of the H locus in heterokaryosis in Rhizoctonia solani. Phytopathology 66:1348-1353.

37. Rayner, A. D. M., and Boddy, L. 1986. Population structure and the infection biology of wood decay fungi in living trees. Adv. Plant Pathol. 5:119-160.

38. Rayner, A. D. M., Coates, D., Ainsworth, A. M., Adams, T. J. H., Williams, E. N. D., and Todd, N. K. 1984. The biological consequences of the individualistic mycelium. Pages 509-540 in: The Ecology and Physiology of the Fungal Mycelium. D. H. Jennings and A. D. M Rayner, eds. Cambridge University Press, Cambridge.

39. Rayner, A. D. M., and Todd, N. K. 1982. Population structure in wooddecomposing basidiomycetes. Pages 109-128 in: Decomposer Basidiomycetes. J. C. Frankland, J. N. Hedger, and M. J. Swift, eds. Cambridge University Press, Cambridge.

40. Sneh, B., Burpee, L. L., and Ogoshi, A. 1991. Identification of Rhizoctonia Species. The American Phytopathological Society, St. Paul, MN.

41. Sneh, B., Jabaji-Hare, S., Neate, S., and Dijst, G. 1996. Rhizoctonia Species: Taxonomy, Molecular Biology, Ecology, Pathology and Disease Control. Kluwer Academic Publishers, Dordrecht, Netherlands.

42. Sweetingham, M. W., Cruikshank, R. H., and Wong, D. H. 1986. Pectic zymograms and taxonomy and pathogenicity of the Ceratobasidiaceae. Trans. Br. Mycol. Soc. 86:305-311.

43. Tommerup, I. C., Barton, J. E., and O'Brien, P. A. 1995. Reliability of RAPD fingerprinting of three basidiomycete fungi: Laccaria, Hydnangium and Rhizoctonia. Mycol. Res. 99:179-186.

44. Vilgalys, R., and Cubeta, M. A. 1994. Molecular systematics and population biology of Rhizoctonia. Annu. Rev. Phytopathol. 32:135-155.

45. Whisson, D. L., Herdina, and Francis, L. 1995. Detection of Rhizoctonia solani AG-8 in soil using a specific DNA probe. Mycol. Res. 99:12991302.

46. Whitney, H. S., and Parmeter, J. R., Jr. 1963. Synthesis of heterokaryons in Rhizoctonia solani Kühn. Can. J. Bot. 41:879-886.

47. Yang, H. A., Sivasithamparam, K., Barton, J. E., and O'Brien, P. A. 1995. Characterization of cereal bare patch isolates of Rhizoctonia solani by random amplified polymorphic DNA analysis. Plant Pathol. 44:811-818.

48. Yang, H. A., Tommerup, I. C., Sivasithamparam, K., and O'Brien, P. A. 1992. Heterokaryon formation with homokaryons derived from protoplasts of Rhizoctonia solani anastomosis group eight. Exp. Mycol. 16: 268-278.

49. Yang, H. A., Zhou, J., Sivasithamparam, K., and O'Brien, P. A. 1992. Variation in cultural morphology and pathogenicity among protoplast-regenerated strains of Rhizoctonia solani. FEMS Microbiol. Lett. 115:83-86.

50. Yang, J., Kharbanda, P. D., Wang, H., and McAndrew, D. W. 1996. Characterization, virulence, and genetic variation of Rhizoctonia solani AG-9 in Alberta. Plant Dis. 80:513-518.

51. Yokoyama, K., and Ogoshi, A. 1988. Studies on hyphal anastomosis of Rhizoctonia solani. V. Nutritional conditions for anastomosis. Trans. Mycol. Soc. Jpn. 29:125-132. 